\title{
Ergonomic Awareness: Simple Solution To Prevent Work-Related Musculoskeletal Disorders (WMSDs)
}

\author{
Khalid Aziz, Ambreen Shehzad, Syeda Tahniyat Ali
}

Musculoskeletal disorders are injuries or dysfunctions that affects muscles, bones, nerves, tendons, ligaments, joints, cartilages, and spinal discs. They include sprains, strains, tears, soreness, pain, carpal tunnel syndrome, hernias, and connective tissue injuries of the structures previously mentioned $^{1}$. Musculoskeletal disorders is a major source of disability and loss of work time among employees ${ }^{2}$. During the last two decades, there is an increase use of Visual Display Units (VDU) in majority of occupation which leads to various work-related musculoskeletal disorders. Musculoskeletal symptoms of VDU users are believed to have a multi-factorial etiology including repetitive motion, excessive force, prolong sitting or standing, workplace ergonomics, excessive physical loads and psychosocial factors $^{3}$.

Most common examples of WMSDs are low back pain, neck pain, carpal tunnel syndrome, tendinitis, epicondilitis etc $^{4}$. Musculoskeletal Disorders affect large numbers of people across most industries and occupations, have the potential to lead to long and serious disability, and impose heavy costs on employers and on society ${ }^{2}$. In order to prevent MSDs a simple ergonomic awareness and approach can reduce the risks and disability among workers in any workplace. According to the International Ergonomics Association (IEA) Council an official definition of the discipline of ergonomics "is the scientific discipline concerned with the understanding of interactions among humans and other elements of a system, and the profession that applies theory, principles, data and methods to design in order to optimize human well-being and overall system performance"2.
To solve all these problems simple strategies can be applied by an organization to enhance their employee's productivity. Re-designing work-stations and use of adjustable furniture are frequently advised ${ }^{5}$. On the other hand, proper posture awareness among workers who are involved in any occupation that demands prolonged static postures especially in front of computers or any visual display units can be carefully trained to differentiate between good and bad postures. Taking regular stretch breaks from sustained positions, monitoring frequency of physical loads, stress management are some of the simplest solutions to adopt by any organization or workplace for the betterment of their workers or employees.

\section{REFERENCES:}

1. Da Costa BR, Vieira ER. Risk factors for work-related musculoskeletal disorders: a systematic review of recent longitudinal studies. American journal of industrial medicine. 2010; 53(3):285-323.

2. Buckle P. Ergonomics and musculoskeletal disorders: overview. Occupational medicine. 2005; 55(3):164-7.

3. Jahanimoghadam F, Abdolalizadeh M. Ergonomics, Musculoskeletal Disorders, and Computer Work. Journal of Health and Biomedical Informatics. 2016; 3(2):145-54.

4. David GC. Ergonomic methods for assessing exposure to risk factors for work-related musculoskeletal disorders. Occupational medicine. 2005; 55(3):190-9.

5. Robertson MM, O’Neill MJ. Reducing musculoskeletal discomfort: effects of an office ergonomics workplace and training intervention. International Journal of Occupational Safety and Ergonomics. 2003; 9(4):491-502. 